\title{
Breve panorama da escassez de água nas bacias hidrográficas do Alto Tietê e do PCJ
}

DOSSIER DAS ÁGUAS : GESTÃo Do PATRIMÔNIO HÍDRICO

\section{Luciana Cordeiro de Souza Fernandes}

Doutora e Mestre em Direito Ambiental pela PUCSP. Professora do Programa de Pós Graduação em Ensino e História das Ciências da Terra, do Instituto de de Geociências da Unicamp, e da Faculdade de Ciências Aplicadas da Unicamp. Limeira [São Paulo] Brasil. <luciana.fernandes@fca.unicamp.br>

\section{Resumo}

A escassez da água na região das bacias hidrográficas do Alto Tietê e dos rios Piracicaba, Capivari e Jundiaí (PCJ), no sudeste brasileiro, é um fato concreto e que deve ser enfrentado, e, a nosso ver não se trata de uma simples crise hídrica, mas de um colapso hídrico anunciado há mais de uma década, o que demonstra um planejamento inconsistente e ineficaz, uma ingerência política e a flagrante ausência do cumprimento dos fundamentos legais trazidos pela Lei da Política Nacional de Recursos Hídricos (Lei Federal n. 9433/97).

\section{Palavras-chave}

água; planejamento hídrico; plano de bacia hidrográfica.

\section{Short overview of water scarcity in the basins of the Upper Tietê River and PCJ}

\begin{abstract}
Water scarcity in the region of the Alto Tietê basin and Piracicaba, Capivari and Jundiaí basins (PCJ), southeastern Brazil, it is a concrete fact that should be faced. In our view it is not a simple water crisis, but a water collapse a decade advertised, which shows an inconsistent and ineffective planning, a lack of political management and the flagrant absence of compliance with the legal grounds brought by the National Water Resources Policy Act (Federal Law n. 9433/97).
\end{abstract}

\section{Keywords}

water; water planning; watershed plan. 


\section{Introdução}

A Constituição brasileira (BRASIL, 1988) não eleva a água a um direito fundamental, a vida é tida como um direito fundamental (art. 5o, caput, CF) e a sadia qualidade de vida é assegurada (art. 225, CF). Assim, o direito à água exsurge como o conteúdo mínimo do direito à dignidade da pessoa humana (art. 1ํㅡㄴ III, CF), a qual somente poderá ser obtida com água em quantidade e qualidade.

Falando em quantidade, é cediço que a quantidade da água no planeta é a mesma desde o início dos tempos, os fatores preocupantes com relação a este precioso bem ambiental se referem a sua distribuição espacial, sua disponibilidade e, principalmente, a sua qualidade.

Embora tenhamos um avançado arcabouço legal para gestão e proteção das águas no Brasil, ainda há muito a fazer. Possuímos cerca de 13,7\% (ANA, 2011) de toda água doce do planeta, distribuídas irregularmente na superfície e subsolo do vasto território nacional, que necessitam de cuidado e de um maior conhecimento técnico das características de suas inúmeras fontes, pois estamos a comprometer esta imensa riqueza hídrica.

Ao falarmos de água, não podemos discutir o tema de forma isolada, sem levar em consideração o solo, a flora, o ar atmosférico e todos os efeitos da poluição sobre estes bens ambientais.

Vivemos um momento emblemático no país, aumento das temperaturas, El Niño, La Niña e tantos outros fatores climáticos que aliados ao desmatamento, erosão e assoreamento de rios, poluição e contaminação de corpos hídricos superficiais e subterrâneos afetam o equilíbrio hídrico no Brasil, gerando a escassez da água em diversas regiões. No entanto, apesar de todos estes fatores, devem ser somados a este quadro, a ingerência e o planejamento inadequado na gestão dos recursos hídricos, evidenciados na região sudeste onde se localizam as bacias hidrográficas do Alto Tietê e dos rios Piracicaba, Capivari e Jundiaí (PCJ). Esta região é a mais populosa do Brasil, com inúmeras atividades econômicas, com especial destaque às industriais, que demandam grande volume de água para seus processos produtivos. E, embora tais bacias sejam pioneiras no estabelecimento e criação dos Planos e Instrumentos de Gestão dos Recursos Hídricos no país, a escassez da água parece que chegou para ficar.

\section{O que aconteceu?}

Vamos discutir um pouco a este respeito, apresentando inicialmente as características destas duas bacias hidrográficas e do Sistema Cantareira que as une, bem como as medidas e propostas técnicas e jurídicas que estão sendo efetivadas para o enfrentando deste colapso hídrico, que afeta principalmente as populações mais vulneráveis, além de causar impactos a saúde, a economia entre outros.

\section{Da bacia hidrográfica dos rios Piracicaba, Capivari e Jundiaí (PCJ)}

A região das bacias dos rios Piracicaba, Capivari e Jundiaí (PCJ) alcança parte do interior do estado de São Paulo e alguns municípios do sul do estado de Minas Gerais (Figura 1), em uma área de $11.020 \mathrm{~km}^{2}$ (PERH, 2010), abrangendo áreas de 76 municípios $^{1}$ dos quais 62 têm sede nas áreas de drenagem da região. Desses, 58 estão no Estado de São Paulo e 4 em Minas Gerais. Dos municípios que têm território na região PCJ e sede em outras bacias, 13 estão em São Paulo e 1 em Minas Gerais. Com aproximadamente 5 milhões de habitantes, a região é considerada uma

\footnotetext{
${ }^{1}$ São eles os municípios: Águas de São Pedro, Americana, Amparo, Analândia, Artur Nogueira, Atibaia, Bom Jesus dos Perdões, Bragança Paulista, Cabreúva, Campinas, Campo Limpo Paulista, Capivari, Charqueada, Cordeirópolis, Corumbataí, Cosmópolis, Elias Fausto, Holambra, Hortolândia, Indaiatuba, Ipeúna, Iracemápolis, Itatiba, Itupeva, Jaguariúna, Jarinu, Joanópolis, Jundiaí, Limeira, Louveira, Mairiporã, Mombuca, Monte Alegre do Sul, Monte Mor, Morungaba, Nazaré Paulista, Nova Odessa, Paulínia, Pedra Bela, Pedreira, Pinhalzinho, Piracaia, Piracicaba, Rafard, Rio Claro, Rio das Pedras, Saltinho, Salto, Santa Bárbara D’Oeste, Santa Gertrudes, Santa Maria da Serra, Santo Antônio de Posse, São Pedro, Socorro, Sumaré, Tuiuti, Valinhos, Vargem, Várzea Paulista, Vinhedo.
} 
das mais importantes do Brasil devido ao seu desenvolvimento econômico, que representa cerca de 7\% do Produto Interno Bruto (PIB) Nacional (AGÊNCIA PCJ, 2015).

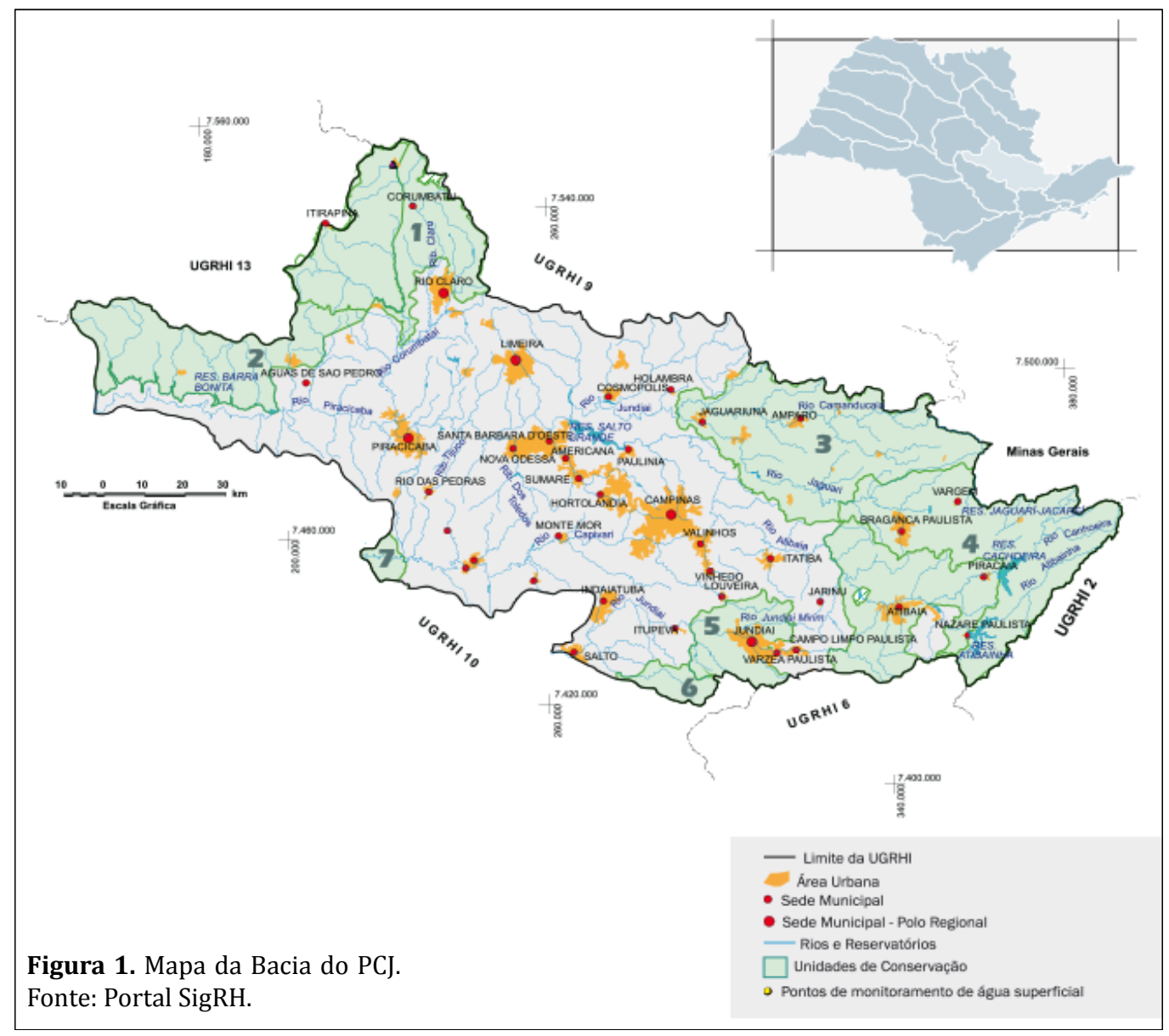

A gestão nesta bacia iniciada pelo Consórcio PCJ em 1989 foi complementada com a criação dos Comitês das Bacias Hidrográficas PCJ (CBH-PCJ, Estadual SP em 1993; Comitê Federal PCJ, em 2003 e CBH-PJ, Estadual MG, em 2008).

Segundo dados da Agência de Bacia do PCJ (2015), as taxas geométricas de crescimento previstas para as populações urbanas da região, são decrescentes, passando de $2,09 \%$ a.a., no período $2000 / 2005$, para 1,19\% a.a., no período 2015/2020. E o grau de urbanização da população será crescente, passando de 93,2\%, em 1996, para 96,8\%, no ano 2020. E somente a sub-bacia do Rio Camanducaia é, na região, a que tende ao menor grau de urbanização no período considerado, passando de 73,4\%, em 1996, para 84,0\%, em 2020, respectivamente. Em posição oposta, encontra-se a região da bacia do rio Jundiaí, onde deverá ocorrer o maior grau de urbanização de toda a região PCJ, passando 95,6\%, em 1996, para 98,8\%, em 2020.

Insta salientar que a região geoeconômica da média região PCJ que concentra uma das redes de infra-estrutura de transportes mais importantes do País. Nela destacam-se um denso complexo viário (que tem nas rodovias Anhanguera, Bandeirantes e D. Pedro I sua espinha dorsal), a linha tronco da FERROBAN e o aeroporto de Viracopos, no município de Campinas, o maior em volume de transportes de carga no País. Toda essa infra-estrutura de transportes, ao mesmo tempo que se comporta como suporte do desenvolvimento econômico da região, estimula a urbanização da área, onde já se verificam fortes tendências à conurbação de cidades (AGÊNCIA PCJ, 2015).

As bacias dos rios que compõe o PCJ apresentam, conforme o Plano das Bacias Hidrográficas dos Rios Piracicaba, Capivari e Jundiaí 2010/2020, uma demanda de $36 \mathrm{~m}^{3} / \mathrm{s}(52 \%)$ para abastecimento urbano, $29 \%$ para o industrial e $18 \%$ para o setor rural, sendo que a relação oferta/demanda já 
apresenta, em alguns trechos das bacias, a obrigatoriedade do reuso. A transferência de até $31 \mathrm{~m}^{3} / \mathrm{s}$ de água da bacia do rio Piracicaba, através do Sistema Cantareira (reservatórios de Atibainha, Cachoeira e Jaguari/Jacareí), para o abastecimento de 50\% da RMSP, localizada na bacia do Alto Tietê, completa o quadro de importância dos recursos hídricos dessas bacias no contexto econômico nacional (CONSÓRCIO PCJ, 2013).

Vale anotar que em 1974 para inauguração e funcionamento do Sistema, antes mesmo da constituição das bacias hidrográficas da forma como hoje estão concebidas, logo após a construção do Sistema Cantareira, a Portaria do Ministério das Minas e Energia autorizou a concessão, por 30 anos, para transposição de águas da bacia do rio Piracicaba, em até 31 mil litros de água por segundo, para abastecer a Grande São Paulo, através do Sistema Cantareira. Transposição poderia chegar a 33 mil litros por segundo, incluindo reservatório de Paiva Castro.

No entanto, atualmente, a renovação da outorga do Sistema Cantareira vem encontrando grande resistência e os debates vêm se acirrando, pois falta água também na Bacia do PCJ. Recentemente, a Secretaria Executiva do Consórcio PCJ (AGUA, 2015a) elaborou um documento intitulado "Sugestões da Secretaria Executiva do Consórcio PCJ para a Renovação da Outorga do Sistema Cantareira", que contém quatro propostas centrais e mais oito ações condicionantes. As sugestões foram apresentadas em julho/2015 às Câmaras Técnicas (CTs) dos Comitês PCJ, que concordaram e incluíram grande parte delas nas recomendações a serem enviadas ao plenário do Comitê. As quatro sugestões centrais deste documento foram apoiadas pelas CTs: extinção do Banco de Águas e criação de reserva estratégica única, gerenciada pelos órgãos gestores e consultados os comitês de bacias; atualização da vazão limite de retirada, que deverá ter como base as curvas de aversão a risco, levando-se em conta e acrescentando a ocorrência climática de 2013/2014; criação de curvas de aversão a enchentes; e divisão proporcional ao número de habitantes das regiões hidrográficas envolvidas da água acumulada nos reservatórios do Sistema Cantareira.

Segundo o Prof. Dr. Antônio Carlos Zuffo (AGUA, 2015a), da Universidade Estadual de Campinas, a divisão proporcional da água ainda levará em conta a redução da capacidade de regularização da água do Sistema Cantareira para garantir o abastecimento de água com 95\% de segurança, a vazão máxima de retirada seria de apenas $34 \mathrm{~m}^{3} / \mathrm{s}$ ante os atuais $36 \mathrm{~m}^{3} / \mathrm{s}$ autorizados. Com base nisso, as vazões limites para a Região Metropolitana de São Paulo deverão ser adaptadas a essa nova realidade. Assim, a divisão se daria na seguinte proporção: $24 \mathrm{~m}^{3} / \mathrm{s}$ para a Região Metropolitana de São Paulo e $10 \mathrm{~m}^{3} / \mathrm{s}$ para o PCJ, respeitando, deste modo, a proporcionalidade do número de habitantes atendidos, sendo nove milhões na RMSP (69\%) e cerca de quatro milhões nas Bacias do Piracicaba e Jundiaí (31\%), noticiou o Consórcio PCJ.

\section{Da bacia hidrográfica do Alto Tietê}

A bacia hidrográfica do Alto Tietê abrange a capital e a região metropolitana de São Paulo (Figura 2), com área de drenagem de $5.650 \mathrm{~km}^{2}$ (PERH, 2010), composta de 36 municípios, a saber: Arujá, Barueri, Biritiba Mirim, Caieiras, Cajamar, Carapicuíba, Cotia, Diadema, Embu, Embu-Guaçu, Ferraz de Vasconcelos, Francisco Morato, Franco da Rocha, Guarulhos, Itapecerica da Serra, Itapevi, Itaquaquecetuba, Jandira, Juquitiba, Mairiporã, Mauá, Mogi das Cruzes, Osasco, Pirapora do Bom Jesus, Poá, Ribeirão Pires, Rio Grande da Serra, Salesópolis, Santana do Parnaíba, Santo André, São Bernardo do Campo, São Caetano do Sul, São Lourenço da Serra, São Paulo, Suzano, Taboão da Serra. Tendo em vista que esta região é densamente urbanizada, dados estatísticos estimam uma população de quase vinte milhões de habitantes conforme dados do SEADE (2013). A bacia hidrográfica do Alto Tietê depende da transposição de águas da bacia hidrográfica do PCJ para o Sistema Cantareira.

\section{Do Sistema Cantareira}

Em 1962, foi criada a Comissão Especial para o Planejamento das Obras de Abastecimento e Distribuição de Água da Capital (CEPA), que iniciou os primeiros estudos concretos para o aproveitamento das águas do Rio Juqueri, denominado Sistema Juqueri, depois Sistema Cantareira (CEON, 1967). 


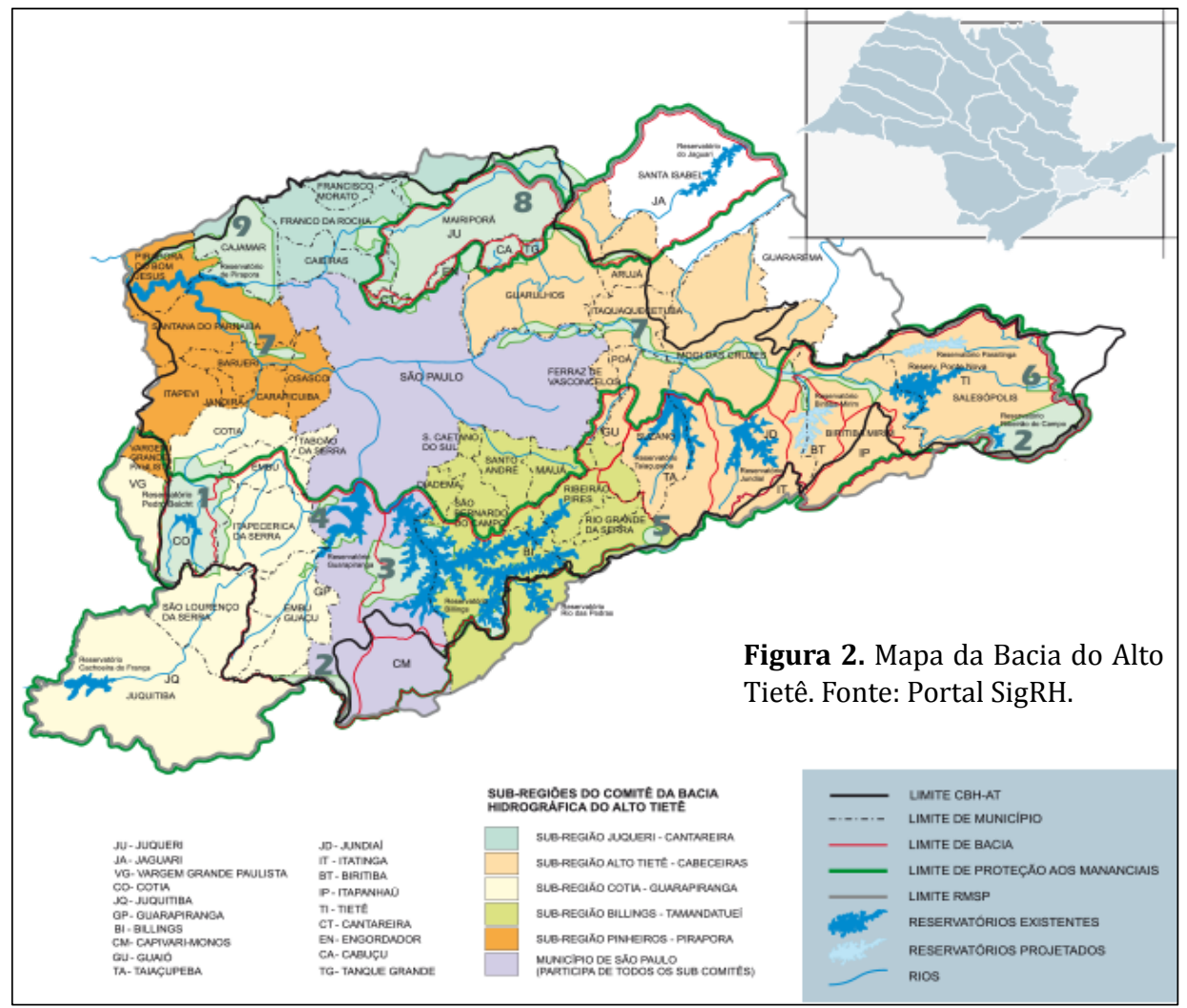

Segundo a Agência Nacional de Águas (ANA, 2015), o Sistema Cantareira constitui o maior sistema produtor de água da Região Metropolitana de São Paulo (RMSP), responsável pelo abastecimento de cerca de nove milhões de pessoas na Capital e nos municípios de Franco da Rocha, Francisco Morato, Caieiras, Guarulhos (parte), Osasco, Carapicuíba, Barueri (parte), Taboão da Serra (parte), Santo André (parte) e São Caetano do Sul. Além disso, a água liberada a jusante (abaixo) dos reservatórios do Sistema Cantareira contribui para a regularização dos rios Jaguari, Cachoeira e Atibainha, na bacia do rio Piracicaba, onde existem diversas captações para abastecimento urbano e industrial.

O Sistema Cantareira (Figura 3) abrange seis reservatórios, ligados por túneis e canais: JaguariJacareí, Cachoeira, Atibainha, Paiva Castro e Águas Claras. Os quatro primeiros estão localizados em afluentes do rio Piracicaba, que fica na bacia hidrográfica do PCJ (Piracicaba, Capivari e Jundiaí) e os dois últimos reservatórios, localizados na bacia hidrográfica do Alto Tietê, tendo como objetivo reter e transpor água para a Estação de Tratamento de Água (ETA) Guaraú.

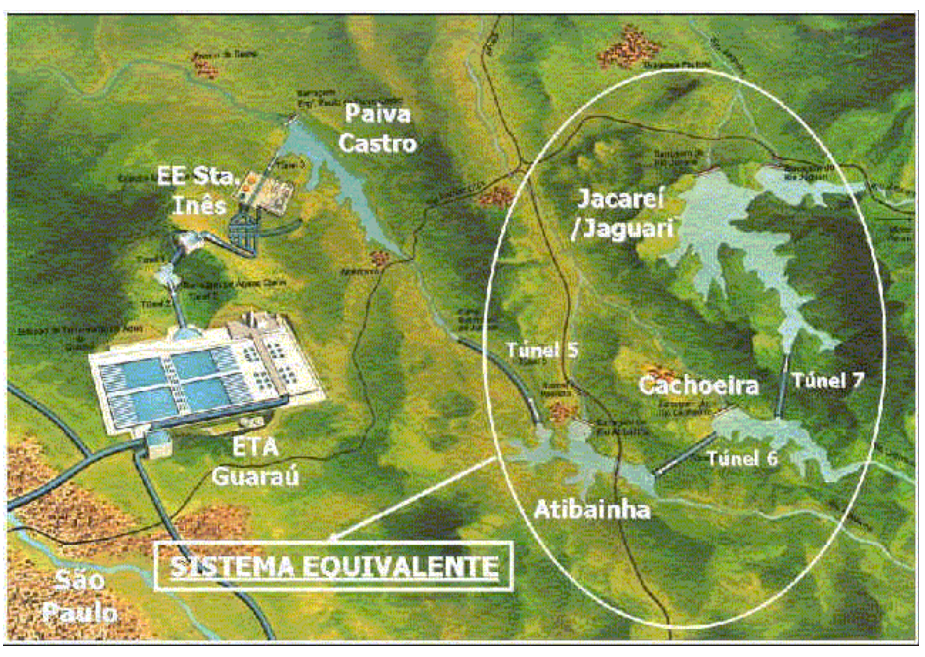

Devido aos critérios de dominialidade das águas estabelecidos pelo artigo 20, inciso III, e pelo artigo 26, inciso I da Constituição Federal (BRASIL, 1988), duas das barragens são de gestão federal (Jaguari e Cachoeira) e as demais (Jacareí, Atibainha, Paiva Castro e Águas Claras) são de gestão do estado de São Paulo (Figuras 4 e 5).

Figura 3. Sistema Cantareira. Fonte: Agência Nacional de Águas, Departamento de Águas e Energia Elétrica. 


\section{Sistema Cantareira}

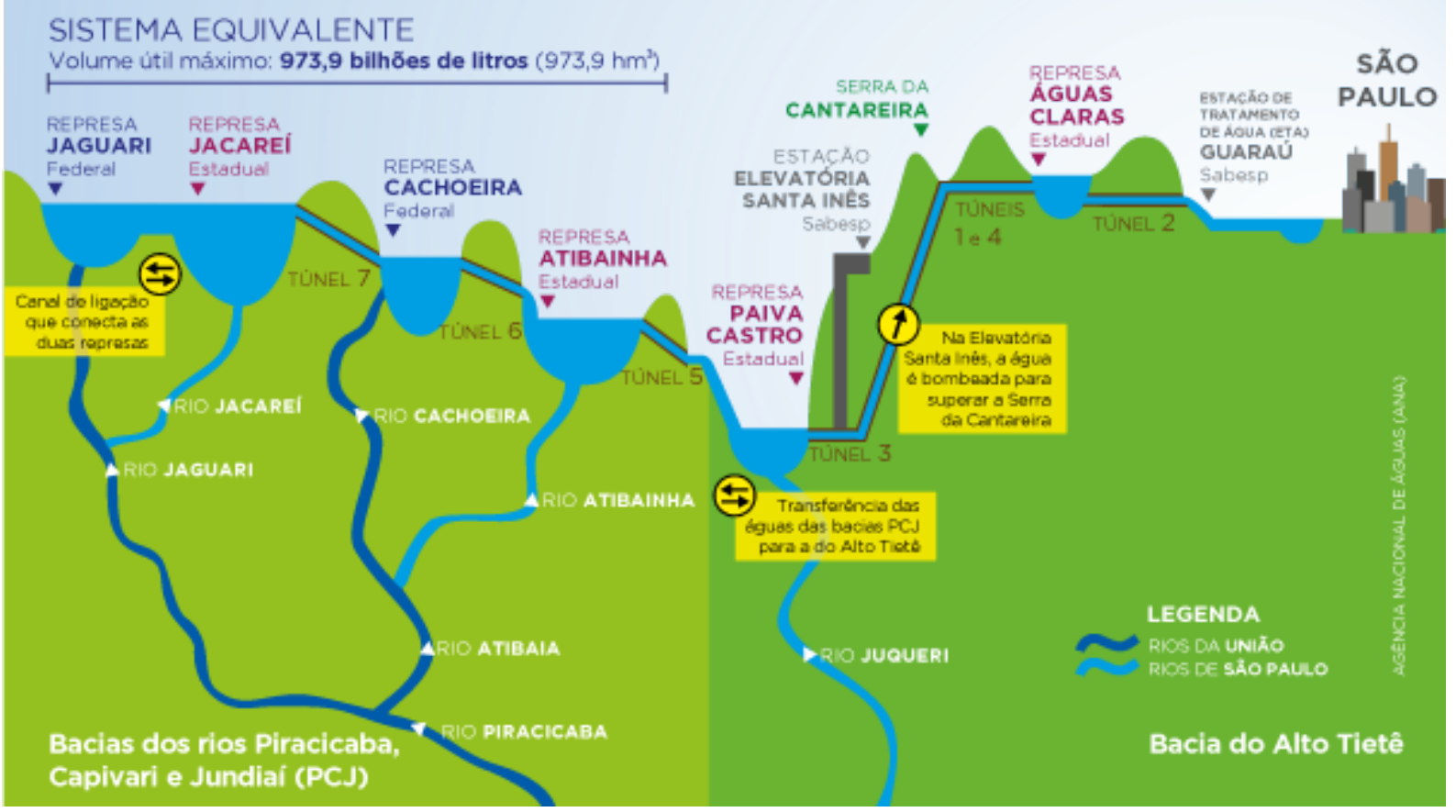

Figura 4. Sistema Cantareira. Fonte: Agência Nacional de Águas (ANA).

\section{Entenda: Sistema Cantareira de abastecimento e a chuva em SP}
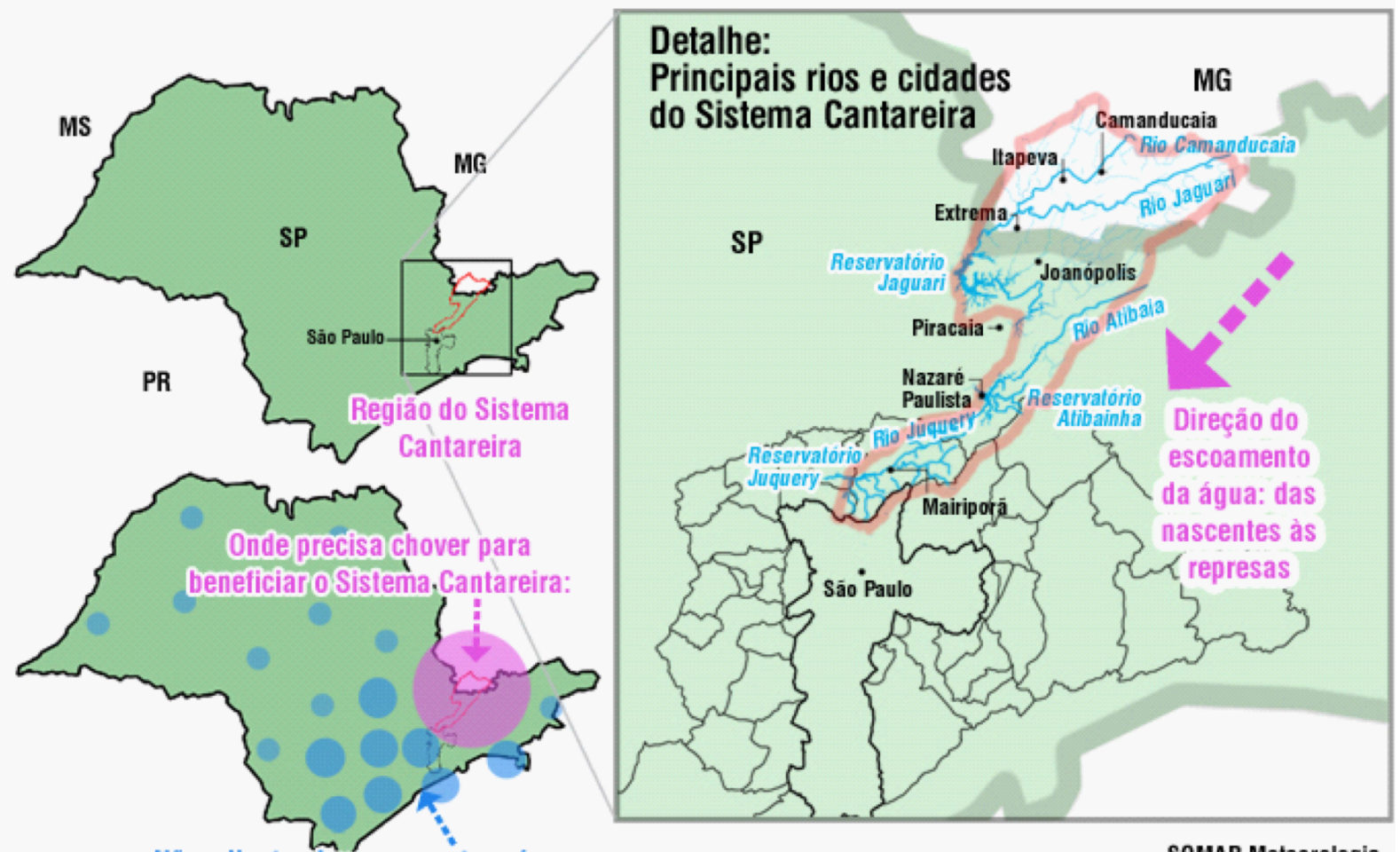

Não adianta chover em outras áreas...

SOMAR Meteorologia

Figura 5. Sistema Cantareira. Fonte: SOMAR Metereologia. 
Quase todo Sistema é operado por gravidade, ou seja, a água vai de um reservatório para outro com a força da gravidade e somente após alcançar a Represa Paiva Castro é conduzida por meio da Estação Elevatória Santa Inês à represa Águas Claras na capital paulista, onde é tratada e servida nas regiões norte e oeste da cidade de São Paulo.

Conforme já explicitado, para manter este Sistema em funcionamento, desde 1974 é necessária a transposição de águas da Bacia Hidrográfica do PCJ para o Cantareira.

A gestão do Sistema Cantareira é realizada pela Companhia de Saneamento Básico do Estado de São Paulo - SABESP, empresa de economia mista controlada pelo Governo do Estado de São Paulo, detentor de $51 \%$ das ações. A partir de 2002 suas demais ações passaram a ser negociadas na Bovespa e, em seguida na Bolsa de Nova York. Muitos criticam sua gestão, notadamente porque ao invés de investir no Sistema optou por pagar os dividendos aos acionistas, compondo mais uma das causas para o colapso hídrico experimentado pela população que depende do Cantareira.

Segundo informa a ANA (2015) e amplamente noticiado por todas as mídias com imagens que mais parecem retratar a seca do sertão nordestino, dado o agravamento da estiagem no Sistema está sendo utilizada a reserva técnica do Sistema Cantareira, conhecida como "volume morto", que soma cerca de 480 bilhões de litros de água localizados abaixo das estruturas de operação dos reservatórios e acessíveis apenas por bombeamento. Assim, em 16 de maio de 2014, por meio do Comunicado Conjunto ANA-DAEE n. 233, foi autorizado o bombeamento de volumes de água dos reservatórios Jaguari-Jacareí. Em 7 de julho de 2014, a Resolução Conjunta ANA-DAEE n. 910 autorizou o bombeamento nos demais reservatórios da bacia do rio Piracicaba. E, em outubro de 2014, a Sabesp solicitou ao DAEE autorização para captar uma segunda cota da reserva estratégica. A autorização para o uso foi concedida pelos órgãos reguladores em novembro de 2014 por meio da Resolução Conjunta ANA/DAEE n. 1672 que definiu novas cotas limite para o bombeamento de água, pela Sabesp, nos reservatórios Jaguari-Jacareí, Cachoeira e Atibainha. Diferente da autorização para o uso da primeira parcela do volume morto, a nova Resolução autorizou a utilização de volumes adicionais por parcelas, definidos por meio de Comunicados Conjuntos ANA-DAEE.

Como visto, a operação deste Sistema é realizada pela SABESP, que ao longo dos últimos 2 anos de "crise" está sendo monitorada dia a dia pela ANA (Agência Nacional de Águas) e pelo DAEE (Departamento de Águas e Esgoto de São Paulo) que, de forma conjunta, determinam os limites de retirada de água do Sistema. Recentemente foi anunciado através do Comunicado Conjunto ANA/DAEE n. 248/2015, que as vazões praticadas pela SABESP nos próximos 4 meses sofrerão variação, sendo que de $1^{\circ}$ a 31 de agosto/2015 a máxima média mensal será de $14,5 \mathrm{~m}^{3} / \mathrm{s}$; entre 1 o de setembro e 31 de outubro/2015, a companhia poderá retirar até $13,5 \mathrm{~m}^{3} / \mathrm{s}$ do Sistema; e em novembro/2015 essa vazão cai para $10 \mathrm{~m}^{3} / \mathrm{s}$. E para a Bacia Hidrográfica do Rio Piracicaba o Comunicado prevê a manutenção da máxima média de $3,5 \mathrm{~m}^{3} / \mathrm{s}$ até 30 de novembro de 2015 , conforme indicaram os estudos técnicos.

\subsection{A vegetação na área do Sistema Cantareira}

Vale anotar neste tópico a questão do desmatamento na área do Sistema Cantareira, região que deveria ter uma grande e preservada cobertura vegetal, posto ser produtora e conservadora de água. Ora, sem floresta não há água!

A SOS Mata Atlantica procedeu a levantamentos florísticos nesta área, constatando grande perda de vegetação nativa no entorno dos reservatórios e em toda região do Sistema Cantareira (HIROTA, 2014), conforme podemos observar na imagem abaixo (Figura 6) e nos dados que subsidiaram a elaboração da tabela.

A legislação florestal brasileira prevê que as áreas do entorno de um reservatório são consideradas áreas de preservação permanente e devem ser preservadas, principalmente, em áreas de tamanha importância como o entorno do Cantareira. 
[...] O importante papel desempenhado pela vegetação na proteção dos corpos d'água confere às matas ciliares um grande aparato de leis, decretos e resoluções visando a sua preservação e recuperação, sendo consideradas áreas de preservação permanentes legais. [...] No contínuo e desregrado processo de urbanização, as matas ciliares sofrem pressão antrópica, pois comumente estas áreas são escolhidas para ocupação indevida com construção de moradias, que nos períodos de deflúvio intenso sofrem as consequências das enchentes.

[...] As matas ciliares são áreas de preservação permanente e constituem espécies de espaços territoriais especialmente protegidos, previstos pelo inciso III do $\S 1^{\circ}$ do art. 225 da $C F / 88$ (SOUZA e FERNANDES, 2010: 223, 226, 227).

Remanescentes Florestais da Mata Atlântiça 2013

Bacia Hidrográfiça do Cantareira

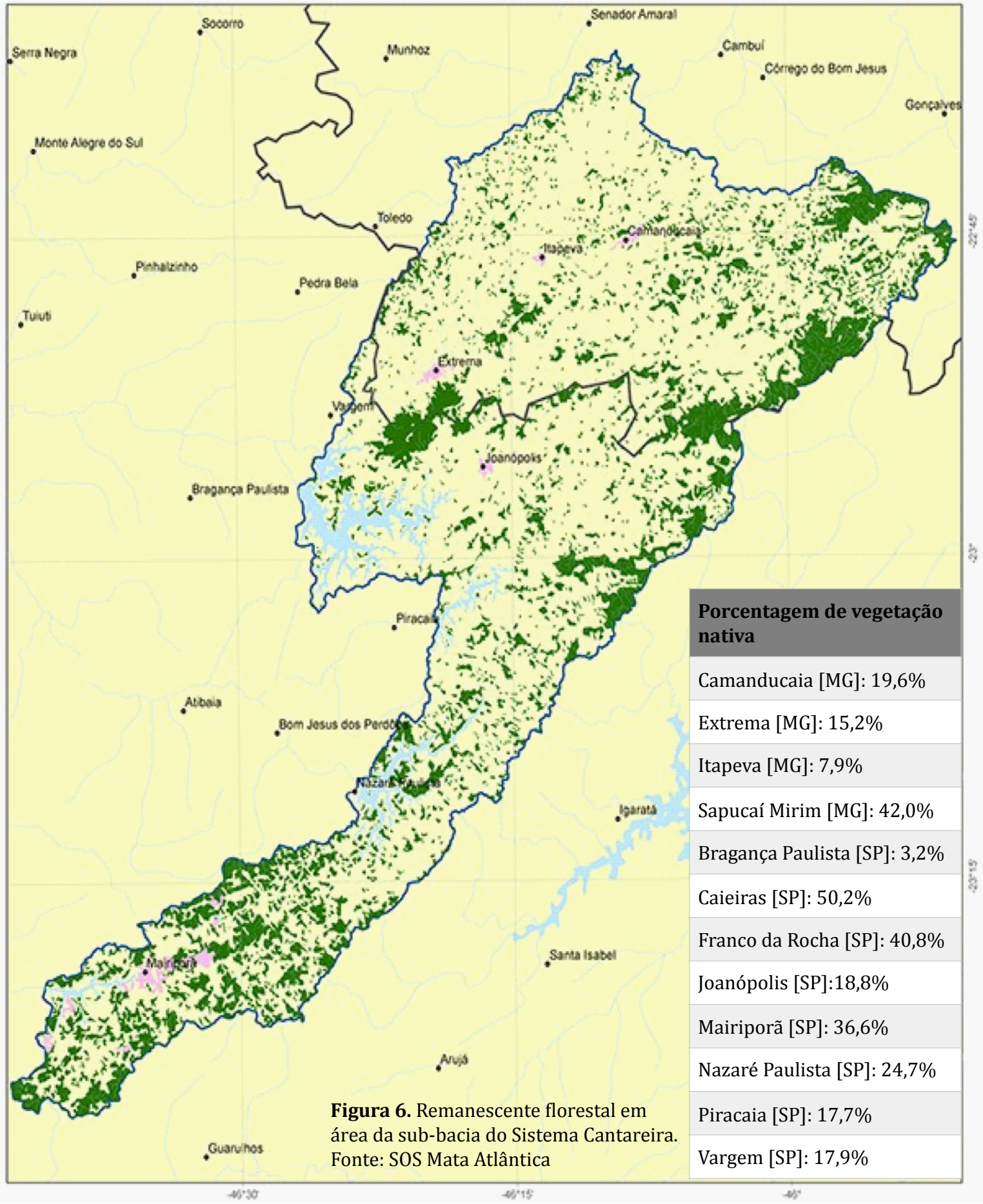


Diante desse quadro de desrespeito as leis existentes e da grande importância das matas ciliares, da simbiose existente entre água e floresta, urge que ações efetivas sejam adotadas nesta área visando o reflorestamento e a recuperação da vegetação, notadamente no entorno dos reservatórios e nascentes nesta região.

\section{Crise anunciada}

Vamos tomar como ponto de partida desta "crise", a notícia veiculada no caderno Cotidiano da Folha de São Paulo, datada de 12/10/2003, embora diversos estudos técnicos já anteviam este cenário. Nesta reportagem a manchete estampava “SP só atende demanda de água até 2010 ", era um período em que vivíamos uma crise da água e alguns dos reservatórios do Sistema Cantareira encontravam-se secos. Nesta reportagem destacava-se a época que:

A crise de água que a Grande São Paulo vive hoje não é a primeira nem será a última. Por causa de limites naturais na disponibilidade hídrica, da poluição de rios e represas, da ocupação desordenada de mananciais, do descaso no uso e da falta de políticas eficientes para reeducar o consumo e reduzir perdas, a região só tem água garantida até 2010 (VIVEIROS e IWASSA, 2003).

No entanto, apesar desta situação anterior, o Sistema não foi remodelado nem outros reservatórios criados, ou seja, nada foi feito. Por isto, Giovanni (2015) enfatiza não se tratar de uma crise, mas de um colapso, posto que anunciado.

Ao contrário do que governos, imprensa e até organizações ambientalistas afirmam, não existe nenhuma crise hídrica no Brasil. Classificar o que está acontecendo com os recursos hídricos nos maiores Estados do país como "crise" é reduzir e limitar a real compreensão dos fatos. Crises são acontecimentos abruptos e momentâneos. Um momento difícil na existência, quando enfrentamos - na maioria das vezes - situações quase sempre alheias a nossa vontade. A falta de água não é uma "crise", porque ela não é fruto de um acontecimento imprevisível. Não se trata de um capricho de São Pedro que, de uma hora para outra, resolveu castigar a Região Sudeste. Há mais de 10 anos os governos tinham informações técnicas confiáveis que as torneiras iriam secar a médio prazo (GIOVANNI, 2015).

Entretanto, somente após este estado de escassez se consolidar, verificamos que ações técnicas foram realizadas no intuito de promover a gestão dos recursos hídricos ainda disponíveis.

Neste sentido, inicialmente a ANA e o DAEE suspenderam temporariamente a concessão de outorgas de captações de águas superficiais na área paulista dos rios Jaguari e Atibaia, formadores do rio Piracicaba, através da Resolução Conjunta ANA/DAEE n. 336 de 05/03/14.

Na sequência, suspenderam as outorgas para captações de água superficiais de domínio da União nas bacias PCJ através da Resolução Conjunta ANA/DAEE n. 699, de 27/05/2014. E o DAEE determinou a suspensão das outorgas para novas captações de águas (superficiais e subterrâneas) de domínio do Estado, localizadas nas áreas das bacias do PCJ (UGRHI 5) e do Alto Tietê (UGRHI 6), por meio da Portaria DAEE n. 1029, de 21/05/14 (reti-ratificada em 06/06/14).

Nesta esteira, em 21/01/15, por meio de outra Resolução Conjunta ANA/DAEE n. 50, foram estabelecidas as regras e condições de restrição de uso para captações de água nas bacias dos rios Jaguari, Camanducaia e Atibaia, a qual derivou a Portaria DAEE n. 761, de 09/03/15 que veio para estabelecer as condições e os procedimentos a serem adotados pelos usuários para fins de fiscalização, em razão desta Resolução.

Paralelamente, o Governo do Estado de São Paulo sinalizou como alternativa para a "crise" a construção de obras para a transposição das águas do Rio Paraíba do Sul para o Sistema Cantareira. A obra prevê a transposição de 5,1 mil litros por segundo, em média, da Represa Jaguari, em Igaratá, que pertence à Bacia do Paraíba do Sul, para o reservatório Atibainha, em Nazaré Paulista, que forma o Sistema Cantareira. Este projeto gerou grande conflito entre os três estados que se servem desta 
bacia hidrográfica: São Paulo, Rio de Janeiro e Minas Gerais, pois o tanto o Rio de Janeiro como Minas Gerais também possuem regiões que enfrentam estresse e escassez hídrica. Desta forma, para dirimir tal conflito, perante o Supremo Tribunal Federal ocorreu a assinatura de um Acordo entre os envolvidos na data de 27/11/14, para a retirada de água desta Bacia. Este acordo permite a São Paulo a contratação das obras para transposição do Rio Jaguari (AMORA, 2014).

No entanto, o Tribunal de Contas do Estado de São Paulo suspendeu, em março de 2015, o processo de licitação do projeto de transposição de água da Bacia do Rio Paraíba do Sul para o Sistema Cantareira (ESTADÂO, 2015a). E apesar de toda polêmica e protestos, esta transposição vai ocorrer, conforme se depreende da notícia veiculada em 24/09/2015:

O governador de São Paulo, Geraldo Alckmin (PSDB), anunciou na quarta-feira (23) que a ordem de serviço para o início das obras de transposição da Bacia do Paraíba do Sul para o Sistema Cantareira será iniciada no dia 2. Além disso, a transposição de água do Reservatório Rio Grande, braço limpo da Represa Billings, para reforçar o Sistema Alto Tietê começará na quarta (ESTADÃO, 2015b).

Em todo este período de "crise", tendo em vista as diversas "falhas" de gestão, a ausência de transparência nas ações governamentais, o racionamento de água para as populações vulneráveis e os riscos a saúde em razão do uso do volume morto entre outros fatores, conforme informou a Promotora Dra. Alexandra Faciolli Martins (2015), do Ministério Público Paulista, em palestra proferida no Fórum Sustentabilidade Hídrica (PENSES/UNICAMP) em 18 março de 2015, o Ministério Público Federal e o Ministério Público do Estado de São Paulo, através do GAEMA, junto com a coletividade e diversos técnicos, em um trabalho conjunto, determinaram a criação de mecanismos de articulação:

- GE-ÁGUAS (Grupo Estratégico no MP/SP - Ato n. 106/2014 - PGJ, de 22/07/2014);

- Instauração do Inquérito Civil n. 06/13 que discute a outorga do Sistema Cantareira e aumento da disponibilidade hídrica;

- $\quad$ Expedição de Recomendações (Fevereiro e Abril de 2014);

- Realização e Participação em inúmeras reuniões e audiências públicas com órgãos gestores (ANA/DAEE), SABESP, MP/SP, MPF, usuários, sociedade civil etc., num total de 125 reuniões sobre o tema;

- $\quad$ Ajuizamento pelo MPSP e MPF da Ação Cível Pública - Proc. n. 0005930 92.2014.403.6109 em 02/10/14, junto a 3 ${ }^{\text {a }}$ Vara da Justiça Federal de Piracicaba, tendo como Réus: ANA, DAEE e SABESP, e como objetivos: evitar o esgotamento do Sistema Cantareira (uso indiscriminado do volume morto), buscar a recuperação dos reservatórios e da segurança hídrica, bem como a reorganização do sistema de gerenciamento, com o respeito às atribuições do Comitê das Bacias PCJ, exclusão da SABESP da gestão, assegurando a gestão descentralizada, democrática, participativa e o direito de informação, além de outras diversas providências. Nesta ação o Exmo. Juiz Dr. Miguel Florestano Neto, concedeu a tutela antecipada em 09/10/14. 0 Presidente do TRF da 3a Região, Exmo. Des. Federal Fábio Prieto, suspendeu a liminar requerida pelo Estado de São Paulo em 16/10/14. DAEE e a SABESP impetraram Agravo de Instrumento junto a $4^{a}$ Câmara do Egrégio TRF da $3^{a}$ Região (Proc. n. 0027201-54.2014.4.03.0000) e houve a Redistribuição da Ação Civil Pública n. 0005930-92.2014.4.03.6109 a uma das Varas Federais da Capital do Estado de São Paulo (13a Vara Cível Federal da Capital). A antecipação de tutela foi ratificada em 09/02/15;

- Inquérito Civil n. 14.1096.0000005/2014-2 pelo MP/SP (GAEMA PCJ — Piracicaba e Campinas) funcionamento, a eficiência e eventual necessidade de melhorias no que tange à fiscalização, à gestão e à articulação entre os órgãos públicos competentes (ANA, DAEE, CETESB, Vigilância Sanitária, Agências Reguladoras e SABESP), de modo a garantir a Qualidade e a Potabilidade da água tratada destinada ao abastecimento público e ao consumo humano (saúde pública), bem como o Controle da poluição das águas brutas para a proteção da vida aquática, para a diversidade biológica e a preservação dos ecossistemas nas Bacias dos Rios PiracicabaCapivari e Jundiaí (Bacias do PCJ).

E no tocante a atual outorga de direito do uso das águas dos reservatórios que compõem o Sistema Cantareira venceria em agosto de 2014, mas sua vigência foi prorrogada até 31 de outubro de 2015, por meio da Resolução Conjunta ANA-DAEE no 910, de 7 de julho de 2014. A Agência Nacional de Águas 
(ANA) divulgou nota nessa terça-feira, dia 20 de outubro, informando que a renovação da outorga do Sistema Cantareira, prevista para ser finalizada no dia 30 deste mês, será adiada para maio de 2017 (AGUA, 2015b).

\subsection{Do uso prioritário para consumo humano e dessedentação de animais}

Esta pseudo crise que preferimos chamar de colapso, fere os Fundamentos da Lei da Política Nacional de Recursos Hídricos (LPNRH), dispostos no artigo 1. da Lei 9433/97, notadamente o inciso III.

\section{Art. 1‥ A Política Nacional de Recursos Hídricos baseia-se nos seguintes fundamentos: III - em situações de escassez, o uso prioritário dos recursos hídricos é o consumo humano e a dessedentação de animais (BRASIL, 1997).}

Neste inciso há o reconhecimento da água para o seu uso mais nobre. Segundo estabelece a ONU, menos de $500 \mathrm{~m}^{3} / \mathrm{hab} /$ ano já significa escassez de água e uma disponibilidade hídrica inferior a $1500 \mathrm{~m}^{3} / \mathrm{hab} /$ ano traduz-se em estresse hídrico (REBOUÇAS, 2002). Em recente Seminário realizado pela Comissão de Meio Ambiente da Câmara de Campinas que contou com a presença do MP/SP, MPF, UNICAMP entre outros, ocorrido no dia 22/09/2015, foi elaborado um "Manifesto pela Sustentabilidade Hídrica das Bacias PCJ", do qual destacamos a seguinte e preocupante informação técnica sobre a disponibilidade hídrica nas duas bacias.

Nas Bacias PCJ e Alto Tietê, que possuem, em épocas de estiagem, um alto grau de estresse hídrico, constatou-se a redução da disponibilidade hídrica de 408 para $298,79 \mathrm{~m}^{3} / \mathrm{hab} / \mathrm{ano}$ e de 208 para 49,62 $\mathrm{m}^{3} / \mathrm{hab} /$ ano, respectivamente, valores estes muito abaixo dos $1500 \mathrm{~m}^{3}$ / hab/ano estabelecidos como mínimos pela ONU; [...] (SEMINÁRIO, 2015).

De acordo com estes dados, concretamente, neste momento a escassez está sendo enfrentada pelas bacias do Alto Tietê e PCJ, devendo ser priorizado o uso da água para o consumo humano e a dessedentação dos animais nesta região. A ausência de medidas desta natureza demonstra o total desrespeito a este fundamento legal, posto que embora não haja decretação de racionamento ou sequer anúncio de rodízio por parte do governo do Estado de São Paulo, a realidade é que em muitas localidades, a água não vem sendo servida às populações mais vulneráveis e continua a alimentar as indústrias e outras atividades econômicas prioritariamente. E isto é corroborado por notícias divulgadas pela imprensa.

De acordo com o noticiado pelo Estadão (2014) um levantamento realizado pela SABESP aponta que apenas um grupo de $10 \%$ de clientes da Região Metropolitana de São Paulo continua gastando mais água hoje do que antes da crise hídrica, consumindo em novembro/2014 um volume equivalente a um terço de toda a produção do Sistema Cantareira. São 446.677 consumidores tachados de "gastões" pelo governo Geraldo Alckmin (PSDB) e que estão na mira da proposta de multa apresentada à Arsesp (Agência Reguladora de Saneamento e Energia). E, posteriormente foi constatado que um grupo de apenas 8 (oito) indústrias do interior paulista possuem outorga para captar dos rios uma quantidade de água duas vezes maior que cidade de Campinas com 1,1 milhão de habitantes (RODRIGUES, LABEL, 2015), ou seja, trata-se de flagrante desrespeito ao art. 1ํ, III da LPNRH.

Este fato é tão grave que houve denúncia a Comissão de Direitos Humanos da ONU que enviou uma Comissão para análise do caso.

O novo relator das Nações Unidas sobre a água, o mineiro Leo Heller, se reuniu em São Paulo com vários coletivos sociais, ONGs, promotores, procuradores e acadêmicos preocupados com o impacto da crise hídrica sobre a população, especialmente na região metropolitana. Heller encerrou a jornada surpreendido com alguns depoimentos e anunciou que a relatoria apurará possíveis violações de direitos humanos - especialmente o direito universal de acesso à água e ao esgotamento sanitário, mas também questões derivadas da crise, como o direito à saúde. "Não quero afirmar que já há direitos que estão sendo violados, mas muitos depoimentos vão nessa direção e as consequências têm impacto em milhares de pessoas. Isso é incompatível com uma região com o nível de desenvolvimento de São Paulo", afirmou o relator (MARTÍN, 2015). 
Após esta reunião foi elaborado o documento intitulado "Crise Hídrica e Direitos Humanos - Relatório de Violação dos Direitos Humanos na Gestão Hídrica do Estado de São Paulo" pela Aliança Pela Água, o Coletivo de Luta Pela Água, o Greenpeace e o Instituto Brasileiro de Defesa do Consumidor (IDEC), divulgado em 13/10/15, no qual são apontados os indícios de violação de direitos humanos na gestão hídrica do estado de São Paulo. 0 documento foi encaminhado à relatoria da Organização das Nações (ONU) para Diretos Humanos à Água e Saneamento. Segundo o Relatório, houve falta de transparência nas informações sobre os cortes de água, falta de planejamento, superexploração dos mananciais, redução de investimento em tratamento de esgoto, e aumento indevido da tarifa. 0 documento diz que faltou e ainda falta um plano de emergência para a capital paulista: não há plano destinado a hospitais, escolas, e para órgãos públicos em caso de falta de água e de agravamento da crise.

[...] “O governo tem responsabilidade na medida em que não atendeu aos avisos e aos próprios documentos oficiais que anunciavam a possibilidade dessa crise. [A responsabilidade] vem desde não ter adotado medidas de precaução previstas na legislação e previstas em documentos oficiais, até a forma como lidou com a crise, com falta de transparência, com obscuridade, negando, e até ridicularizando, aqueles que estavam alertando para o perigo", disse Rafael Poço, da Aliança Pela Água (BOCCHINI, 2015).

Diversos são os usos que podemos atribuir a água e a gestão a ser proporcionada deve contemplar os mais diversos usos, tais como o abastecimento humano, dessedentação animal, agrícola: irrigação, hidroeletricidade, abastecimento industrial, recreação e turismo, navegação, pesca e aquicultura, priorizando-se sempre o abastecimento humano e a dessedentação animal, repita-se.

Outrossim, outro dispositivo da PNRH desrespeitado pelo Governo do Estado de São Paulo, refere-se a gestão dos recursos hídricos que deve ser descentralizada e contar com a participação do Poder Público, dos usuários e das comunidades (art. 1.ํ , IV, Lei 9433/97), significando que as decisões não devem ser tomadas no âmbito exclusivamente político, mas sim no Comitê da Bacia Hidrográfica, com a participação de todos os atores. A gestão participativa constitui um método que enseja aos usuários, a sociedade civil organizada, as ONGs e outros agentes interessados a possibilidade de influenciar no processo de tomada de decisões, possibilitando que todos segmentos da sociedade se tornem protagonistas neste processo de gestão das águas doces do Brasil. Desde o início do agravamento deste colapso, todas as decisões foram tomadas em gabinetes políticos, motivando, inclusive, a propositura das citadas ações civis públicas por parte dos Ministérios Públicos Federal e Estadual paulista.

As decisões políticas não podem se afastar dos fatos incontestáveis que se referem ao estado da natureza, da mesma forma que as decisões judiciais e as proposições legislativas devem se ater ao complexo e dependente quadro que compõe o meio ambiente. Para o equilíbrio ecológico há necessidade de uma análise macro das características ambientais, da simbiose existente na natureza, não sendo possivel dissociar os elementos que a compõe. E neste contexto, está presente o homem, que tem a missão de guardião destes bens para a garantia deste equilíbrio. Assim, as decisões não podem ser levianas, movidas por interesses escusos, individualistas ou meramente econômicos, pois sem este preocupar não há desenvolvimento sustentável, e se olharmos a nossa volta, poderemos constatar que a história recente oferece incontáveis exemplos de danos irreversíveis ao meio ambiente, tendo vitimado, inclusive, milhares de seres humanos (SOUZA, 2012: 258).

\section{Conclusões}

Como vimos a escassez hídrica que a população das bacias hidrográficas do Alto Tietê e dos rios Piracicaba, Capivari e Jundiaí (PCJ) está experimentando, não se refere a uma simples crise da água, mas a um verdadeiro colapso hídrico, fruto de uma má gestão, com ausência de investimentos e desprezo aos estudos técnicos e evidências que anteviam este cenário.

O Sistema Cantareira, construído no início da década de 1970 e formado por seis grandes reservatórios, é o elo de união entre estas bacias hidrográficas, porém não suporta a alta densidade demográfica e as diversas atividades que demandam o uso da água em seus processos produtivos nesta região. Aliado a insuficiência de recursos hídricos, deve ser computada também a perda da vegetação no entorno do Sistema. 
Outro ponto que merece destaque é a ingerência política na gestão dos recursos hídricos nestas Bacias Hidrográficas e o flagrante desrespeito ao princípio da participação, consagrado na Constituição Federal e na LPNRH por meio dos Comitês de Bacias Hidrográficas.

Outrossim, pudemos constatar as diversas Resoluções conjuntas dos órgãos gestores federal e estadual, que visam gerenciar os recursos hídricos disponíveis neste Sistema e na região das Bacias. Além, das ações judiciais propostas em conjunto pelos Ministérios Públicos Federal e Estadual paulista, bem como das manifestações populares a exigir transparência e respeito ao ordenamento legal vigente sobre o tema.

Todavia, verificamos que ao invés de solucionar as questões locais com ações de recuperação da vegetação na área afetada, promover o racionamento de forma equânime e adotar ações de recuperação ambiental na região do Sistema, a solução do atual governo paulista é buscar água de outra bacia hidrográfica, ou seja, tirar água do rio Paraíba do Sul e de uma população que também está com problemas hídricos para repasse desta água para a capital, assim como faz com a retirada do rio Piracicaba. É esta uma solução ou o agravamento e/ou transferência de um problema?

\section{Referências}

AGÊNCIA PCJ. Disponível em http://www.agenciapcj.org.br/novo/informacoes-das-bacias/caracteristicasfisicas/46-informacoes-das-bacias/caracteristicas-geopoliticas - Acesso em 10/10/2015.

AGUA (2015a). Disponível em http://agua.org.br/consorcio-pcj-apresenta-suas-propostas-para-arenovacao-da-outorga-do-sistema-cantareira-as-camaras-tecnicas-dos-comites-pcj/ — Acesso em $10 / 10 / 2015$.

AGUA (2015b). Disponível em http://agua.org.br/ana-adia-renovacao-da-outorga-do-sistema-cantareirapara-maio-de-2017/ - Acesso em 31/10/2015.

AMORA, D. Acordo entre Estados autoriza São Paulo a iniciar transposição do Jaguari. Disponível em http://www1.folha.uol.com.br/cotidiano/2014/11/1554055-acordo-entre-estados-autoriza-sao-paulo-ainiciar-a-transposicao-do-jaguari.shtml - Acesso em 10/10/2015.

ANA. Disponível em http://www2.ana.gov.br/Paginas/servicos/outorgaefiscalizacao/ sistemacantareira.aspx - Acesso em 10/10/2015.

ANA (2011). Panorama Nacional dos Recursos Hídricos In Panorama da água no Brasil. Disponível em http://www.ana.gov.br - Acesso em 08/04/2011.

BRASIL (1988). Constituição da República Federativa do Brasil. Disponível em http:// www.planalto.gov.br/ccivil_03/constituicao/ConstituicaoCompilado.htm - Acesso em 30/10/2015.

BRASIL (1997). Lei da Política Nacional de Recursos Hídricos. Disponível em http:// www.planalto.gov.br/ccivil_03/LEIS/L9433.htm - Acesso em 30/10/2015.

BELORIOPIRACICABA. Disponível em https://beloriopiracicaba.wordpress.com/historia-bacias-pcj/ — Acesso em 24/10/2015.

BOCCHINI, B. Relatório denuncia violação de direitos humanos na crise da água em São Paulo. Agência Brasil, in ECODEBATE, 14/10/2015. Disponível em http://www.ecodebate.com.br/2015/10/14/ relatorio-denuncia-violacao-de-direitos-humanos-na-crise-da-agua-em-sao-paulo/ - Acesso em $24 / 10 / 2015$.

CEON - Comissão Especial de Obras Novas. As obras do Sistema Juqueri - 1aㅡ etapa. In: Revista DAE, n. 65, junho de 1967.

CONSÓRCIO PCJ. Disponível em http://agua.org.br/apresentacoes/71557_ApostilaCantareiraConsorcioPCJ.pdf - Acesso em 24/10/2015. 
ESTADÃO (2014). Sabesp: 10\% dos clientes consomem $\mathbf{1 / 3}$ da produção de água do Cantareira. Disponível em http://noticias.uol.com.br/ultimas-noticias/agencia-estado/2014/12/31/10-dos-clientesconsomem-13-de-toda-a-producao-de-agua-mensal-do-cantareira.htm - acesso em 24/10/2015.

ESTADÃO (2015a). Principal aposta de Alckmin contra seca, interligação do Cantareira é suspensa após pedido de construtora. Disponível em http://noticias.r7.com/sao-paulo/principal-aposta-dealckmin-contra-seca-interligacao-do-cantareira-e-suspensa-apos-pedido-de-construtora-14032015 — Acesso em 24/10/2015

ESTADÃO (2015b). Obra de transposição do Paraíba do Sul para o Cantareira começa em outubro. Disponível em http://noticias.uol.com.br/ultimas-noticias/agencia-estado/2015/09/24/obra-polemicade-transposicao-do-paraiba-do-sul-para-o-cantareira-tera-inicio.htm, acesso em 31/10/2015.

GIOVANINI, Dener. Crise Hídrica? Que crise? Não existe nenhuma crise hídrica! Disponível em http:// sustentabilidade.estadao.com.br/blogs/dener-giovanini/crise-hidrica-que-crise-nao-existe-nenhumacrise-hidrica/ - Acesso 04/09/2015.

GREENPEACE. Crise Hídrica e Direitos Humanos - Relatório de Violação dos Direitos Humanos na Gestão Hídrica do Estado de São Paulo. Disponível em http://issuu.com/saladecrise3/docs/ greenpeace_relatorio_hidrica_a4 - Acesso em 24/10/2015.

MARTÍN, M. ONU vai apurar se crise hídrica viola direitos humanos em São Paulo. El País, 29.04.2015. Disponível em http://brasil.elpais.com/brasil/2015/04/29/politica/1430341927_144411.html — Acesso em $24 / 10 / 2015$.

MARTINS, A. F. Disponível em https://www.youtube.com/watch? v=ZvDL_tl_iM8\&list=PLzhxYAii0R0139ukeWA3tEEqSOpyJ8U7g\&index=19 - Acesso em 31/10/2015.

MARTINS, A.F. Disponível em https://www.youtube.com/watch?v=ILWLlaWObcY — Acesso em 31/10/2015.

PERH. (2010a). Disponível em http://www.daee.sp.gov.br/acervoepesquisa/perh/perh90/ Perh9012b.htm\#PERHIII_2_3 - Acesso em 24/10/2015.

PERH. (2010b). Disponível em http://www.daee.sp.gov.br/acervoepesquisa/perh/perh90/ Perh9012b.htm\#PERHIII_2_1 - Acesso em 24/10/2015.

REBOUÇAS, A. C. Águas subterrâneas. In: REBOUÇAS, Aldo da Cunha; BRAGA, Benedito; TUNDISI, José Galizia. Águas doces do Brasil - capital ecológico, uso e conservação. $2^{\underline{a}}$ ed. rev. amp., São Paulo: Escrituras Editora, p. 119-151, 2002.

SEMINÁRIO (2015). Disponível em http://luizrossini.com/seminario-da-comissao-de-meio-ambiente-daorigem-ao-manifesto-que-servira-de-base-para-renovacao-da-outorga-docantareira/ - Acesso em $31 / 10 / 2015$.

RODRIGUES, A. LOBEL, F. Oito indústrias de SP têm o dobro da água de toda a cidade de Campinas. Disponível em http://www1.folha.uol.com.br/cotidiano/2015/05/1624047-oito-industrias-de-sp-tem-odobro-da-agua-de-toda-a-cidade-de-campinas.shtml — Acesso em 29/10/2015.

SEADE (2013). Disponível em http://www.seade.gov.br/ — Acesso em 24/10/2015.

SIGRH. Disponível em http://www.sigrh.sp.gov.br/cbhat/apresentacao — Acesso em 24/10/2015.

HIROTA. M. Porque desmatar 79\% da área de mananciais secou São Paulo. Disponível em http:// epoca.globo.com/colunas-e-blogs/blog-do-planeta/noticia/2014/10/por-que-bdesmatar-79-da-area-demananciaisb-secou-sao-paulo.html - Acesso em 27/04/15.

SOUZA, L.C. Águas doces do Brasil no início do século XXI. In LECEY, E.; CAPELLI, S. (coord.) Revista de Direito Ambiental - RDA. São Paulo: Editora Revista dos Tribunais, ano 17, v. 68, out-dez/2012, p.257-276. 
SOUZA, L. C.; FERNANDES, A.M. Proteção das matas ciliares. In: Solange Teles da Silva; Sandra Cureau; Marcia Dieguez Leuzinger. (Orgs.). Código Florestal: Desafios e perspectivas. São Paulo: Editora Fiuza, 2010, p. 223-237.

VIVEIROS, M.; IWASSO, S. SP só atende demanda por água até 2010. In Folha de São Paulo. Caderno Cotidiano, 12/10/2003. Disponível em http://www1.folha.uol.com.br/folha/ciencia/ult306u10308.shtml — Acesso em 24/10/2015. 